\title{
PREVALÊNCIA DE CASOS DE VIOLÊNCIA NA POPULAÇÃO LGBT+ NO CONTEXTO INTRAFAMILIAR EM TEMPOS DE PANDEMIA DA COVID-19 ${ }^{1}$
}

\author{
PREVALENCE OF VIOLENCE CASES ON LGBT+ POPULATION ON \\ AN INTRA FAMILY CONTEXT IN COVID-19
}

\section{Isadora Ribeiro Meine ${ }^{2}$, Marciele Ferreira Fragoso ${ }^{3}$ e Janaína P Pretto Carlesso ${ }^{4}$}

\section{RESUMO}

Socioculturalmente, a sexualidade é perpetuada com base no padrão heteronormativo, invisibilizando outras orientações sexuais e identidades de gênero. Afligindo a comunidade LGBT+, o preconceito e a estigmatização se mostram presentes, sendo o seio familiar o principal ambiente, repercutindo até em violências. Dito isto, questiona-se como a saúde mental desses jovens encontra-se no momento de pandemia da COVID-19? Sendo assim, o vigente estudo objetiva verificar a prevalência de casos de violência à população LGBT+ no contexto intrafamiliar em tempos de pandemia da COVID-19. Para esse fim, visou-se: contemplar aspectos históricos da violência contra a população LGBT+ e a patologização da homoafetividade; examinar a violência no contexto intrafamiliar contra a população LGBT+, considerando a pandemia por COVID-19 como agravante; e salientar como se dá a atuação da Psicologia em relação à saúde da população LGBT+. Para tanto, foi realizada uma pesquisa bibliográfica por meio de uma revisão integrativa sistemática, em que os conteúdos obtidos foram analisados por meio da análise de conteúdo de Bardin (2011). Como resultado, constatou-se que os fatores estressores aos quais a comunidade LGBT+ é exposta se originam em profundas e multifacetadas raízes, que contribuem, até os dias atuais, em efeitos nocivos à saúde dos sujeitos a ela pertencentes. Observa-se, ademais, a urgência em discutir acerca da violência intrafamiliar contra a população LGBT+ e sobre o papel da Psicologia diante dessa problemática.

Palavras-chave: Violência intrafamiliar, Pandemia, Saúde mental, Psicologia.

\section{ABSTRACT}

Socioculturally, sexuality is perpetuated based on the heteronormative pattern, making other sexual orientations and gender identities invisible. Afflicting the LGBT+ community, prejudice and stigmatization are present, with the family environment being the main environment, with repercussions even in violence. That said, one wonders how the mental health of these young people is at the moment of the COVID-19 pandemic? Thus, the current study aims to verify the prevalence of cases of violence against the LGBT+ population in the intrafamily context in times of the COVID-19 pandemic. To this end, the aim was: to contemplate historical aspects of violence against the LGBT+ population and the pathologization of homo-affectiveness; examine intrafamily violence against the LGBT+ population, considering the COVID-19 pandemic as an aggravating factor; and highlight how Psychology works in relation to the health of the LGBT+ population. For this purpose, a bibliographic research was carried out through a systematic integrative review, in which the contents obtained were analyzed using Bardin's (2011) content analysis. As a result, it was found that the stressors to which the $L G B T+$ community is exposed originate from deep and multifaceted roots, which contribute, to this day, in

1 Trabalho de Iniciação Científica.

2 Acadêmica do curso de Psicologia da Universidade Franciscana - UFN. E-mail: meineisadora@gmail.com 3 Acadêmica do curso de Psicologia da Universidade Franciscana - UFN. E-mail: marciele.frag@gmail.com 4 Docente do curso de Psicologia da Universidade Franciscana - UFN. E-mail: janaina.carlesso@ufn.edu.br 
harmful effects to the health of the subjects belonging to it. There is also an urgent need to discuss intra-family violence against the LGBT+ population and the role of Psychology in this issue.

Keywords: Intra-family violence, Pandemic, Mental health, Psychology.

\section{INTRODUÇÃO}

As relações familiares são acompanhadas de histórias, afetos e interações dos indivíduos que compõem esse laço. Essas relações também são detentoras de estruturas de poder, as quais reforçam a heterossexualidade compulsória. Tais concepções normativas acerca do gênero e da sexualidade atravessam as expectativas familiares em relação ao sujeito que está inserido nesse contexto. Os sujeitos LGBT+, contudo, encontra-se à margem do parâmetro heterossexual normativo tão recorrente nas organizações familiares, tornando-os mais vulneráveis às diversas formas de violência intrafamiliar (SOLIVA; JUNIOR, 2014).

Segundo o Sistema de Informação de Agravos de Notificação (Sinan), no Brasil, pode-se constatar as seguintes características das pessoas LGBT+ com 10 anos ou mais e em situação de violência no período de 2015 a 2017: 50,0\% é Negra (preta+parda); em 89,6\%, não há deficiência/transtorno; em $34,5 \%$ têm escolaridade até o ensino fundamental; a orientação sexual mais violentada é, com 32,6\%, a lésbica; a Identidade de gênero mais agredida é, com 31,7\%, a transexual mulher; o tipo de violência mais recorrente foi, com $75,0 \%$, a Física; o local com maior prepornderância foi, com $61,0 \%$, a residência; o sexo do provável autor da agressão foi, com 66,2\%, o Masculino; e o vínculo com provável autor da agressão mais apontado foi, com 27,2\%, o parceiro íntimo (PINTO et al., 2020).

Comportamentos fóbicos em relação à comunidade LGBT+ são recorrentes e enraizados socioculturalmente. Advindo de múltiplas conjunturas sociais, tais comportamentos evidenciam-se de diversas formas. Dentre elas, estão as "piadinhas", intimidações e cerceamento de direitos, que se caracterizam como casos de violência psicológica - com amplas repercussões à saúde mental das vítimas -, mas podem se concretizar em violências de cunho físico ou mesmo em assassinatos. Acentuando esse fenômeno, o isolamento físico motivado pela pandemia provocada pelo COVID-19 tem sido tomado como medida para limitar o alastramento do vírus e, com isso, os sujeitos acabam se resguardando em suas residências. Vendo-se obrigados ao convívio intenso com seus familiares, os sujeitos LGBT+, encontram-se mais suscetíveis à discriminações e à violências. Buscando intervir nesse contexto, os profissionais da Psicologia podem, por meio de um olhar cauteloso e de uma escuta qualificada, promover não apenas um contexto de acolhimento às vítimas, mas também planejar ações que visem a dissolução da problemática.

Observa-se que a violência é um fenômeno complexo, polissêmico e multifatorial, podendo resultar em consequências na saúde física e mental das vítimas. Violências simbólicas contra a população LGBT+ muitas vezes se desdobram em agressões, que podem ser letais. No entanto, há um 
amplo desconhecimento acerca dessa problemática, que é motivada por uma insuficiência de dados oficiais sobre essa população e uma consoante subnotificação dos casos de violência contra a população LGBT+. Torna-se imensurável as dificuldades no planejamento de políticas públicas para a prevenção de violências contra essa população (PINTO et al., 2020). Assim, surge o seguinte questionamento: como a saúde mental desses jovens encontra-se no momento de pandemia da COVID-19?

Assim sendo, o vigente estudo objetiva verificar a prevalência de casos de violência à população LGBT+ no contexto intrafamiliar em tempos de pandemia da COVID-19. Para esse fim, visou-se: contemplar aspectos históricos da violência contra a população LGBT+ e a patologização da homoafetividade; examinar a violência no contexto intrafamiliar contra a população LGBT+, considerando a pandemia por COVID-19 como agravante; e salientar como se dá a atuação da Psicologia em relação à saúde da população LGBT+.

\section{METODOLOGIA}

Trata-se de um estudo pautado na abordagem metodológica qualitativa. Baseada na interpretação da realidade, sua principal característica é a busca fenomenológica sobre os atores sociais, aos discursos, os significados e a descrição minuciosa desses elementos. Os dados coletados nessa abordagem são descritivos e indutivos, evidenciando-se aspectos psicológicos e sociais, contemplando uma riqueza de detalhes (AUGUSTO, 2013). A pesquisa qualitativa se preocupa com um âmbito não quantificável da realidade, explorando um universo de "significados, motivações, aspirações, crenças, valores e atitudes" (p. 21-22). Tais fatores estão presentes no campo das inter-relações, abrangendo o que concerne à experiência, ao cotidiano e a compreensão de estruturas e instituições enquanto resultados da ação humana (MINAYO, 1994).

Utilizando-se de conteúdos vigentes tanto da literatura tanto teórica como empírica, a coleta de dados foi realizada por meio da metodologia de revisão integrativa sistemática. Com esse instrumento, torna-se possível não apenas uma análise rigorosa, mas também a ampliação do fenômeno estudado. Sendo assim, a amplitude da amostra desses dados é capaz de promover compreensões consistentes e compreensíveis de fenômenos complexos (SOUZA, 2010).

Os dados - coletados de novembro de 2020 até março de 2021 - foram interpretados por meio da análise de conteúdo de Bardin (2011). Tal método corresponde a um conjunto de instrumentos metodológicos extremamente diversificados que visam, por meio da inferência, a interpretação de conteúdos e seus respectivos continentes. Entretanto, apesar do esforço interpretativo da análise de conteúdo oscilar entre os dois pólos do rigor da objetividade e o da fecunda subjetividade, seu método proporciona ao investigador explorar o "escondido, o latente, o não-aparente, o potencial de inédito (do não-dito), retido por qualquer mensagem" (p. 9). Assim, dependente do tipo de fala a qual se dedica e do tipo de interpretação a que se objetiva, a técnica de análise de conteúdos, por meio do uso 
de algumas regras de base, visa ir além do que está aparentemente pronto. Isto pois, ao elaborar hipóteses sob a forma de questões ou de afirmações enquanto diretrizes, irão carecer de uma sistemática verificação para a constatação de sua validade (BARDIN, 2011).

Dentre os materiais utilizados, contou-se com 19 artigos científicos. A seleção deles - nas bases de dados SciELO (Scientific Eletronic Library Online), PePSIC (Periódicos Eletrônicos de Psicologia) e LILACS (Literatura Latino-Americana e do Caribe em Ciências da Saúde) - foi feita por meio de seus anos de publicação, entre os anos 2000 e 2020, nos quais contivessem algum dos seguintes descritores: "psicologia", "violência", "saúde mental", "LGBT” e "COVID-19”. Na Tabela 1, pode-se visualizar o número de publicações encontradas:

Tabela 1 - Número de trabalhos acadêmicos encontrados entre $2000 e$

2020 de acordo com os descritores e as bases de dados utilizados.

\begin{tabular}{cccccc}
\hline Bases de & \multicolumn{5}{c}{ Descritores } \\
\cline { 2 - 6 } dados & Psicologia & Violência & Saúde Mental & LGBT & COVID-19 \\
\hline SciELO & 21.787 & 10.702 & 6.548 & 273 & 2.263 \\
PePSIC & 8.577 & 940 & 389 & 9 & 0 \\
LILACS & 997.285 & 62.712 & 561.586 & 4.949 & 95.417 \\
\hline
\end{tabular}

Como pode-se visualizar a partir da Tabela 1, nas três bases de dados pesquisadas (SciELO, PePSIC e LILACS), o descritor "Psicologia" obteve o maior número de resultados. Em contrapartida, o menor número de resultados encontrados se deu nos descritores "LGBT”, na SciELO e na LILACS, e no "COVID-19" na PePSIC, sendo que, nesta última base de dados, obteve-se o segundo menor resultado em "LGBT". Diante dos achados na Tabela 1, encontrou-se significativo contraste na quantidade de estudos disponíveis nos descritores "Psicologia" e "LGBT".

\section{RESULTADOS E DISCUSSÃO}

\section{ASPECTOS HISTÓRICOS DA VIOLÊNCIA CONTRA A POPULAÇÃO LGBT+ E A PATOLOGIZAÇÃO DA HOMOAFETIVIDADE}

Em sua obra "História da sexualidade I - a vontade de saber", Michel Foucault (1988), realocou o discurso sobre o sexo ao papel da proibição - o qual foi durante séculos atrelado fortemente a uma solidificação de um despropósito sexual - e o centralizou em uma correlação de poder. Para ele (1988), é na relação de poder ramificada que se encontram as sexualidades disseminadas e a proliferação de prazeres específicos.

$\mathrm{O}$ autor defende essa ideia na seguinte afirmação 
... nesse avanço dos poderes, fixam-se sexualidades disseminadas, rotuladas segundo uma idade, um lugar, um gosto, um tipo de prática. Proliferação das sexualidades por extensão do poder; majoração do poder ao qual cada uma dessas sexualidades regionais dá um campo de intervenção ... (FOUCAULT, 1988, p.47).

Noutras palavras, a rotulação do sexo se dá de acordo com diversos fatores sociais e em características distintivas. Dessa forma, a sexualidade se apresenta dentro de uma designação de poder. Estando à margem do que é convencionado pelo padrão heteronormativo, a população LGBT+ torna-se suscetível aos mecanismos estruturais de controle.

O movimento LGBT+ no Brasil surgiu na década de 1970 e é marcado pela luta e resistência contra o estigma e discriminação social sofridas cotidianamente no país, manifestado-se historicamente em três ondas. A primeira delas surgiu após o fim do regime militar brasileiro e baseou-se em preceitos revolucionários da época, momento ditatorial que permeado pela suspensão de direitos civis, na censura, no autoritarismo e na tortura como práticas frequentes. A segunda onda ocorreu na década de 1980 e foi marcada pela participação da comunidade LGBT+ no cenário público. Por fim, a terceira onda ocorreu em 1990 tendo ligação institucional estatal e não-estatal (ALBERNAZ; KAUSS, 2015).

Esse movimento transcorreu tanto em consequência das violências contra a população LGBT+ como pelo não reconhecimento dos direitos civis, legislativos e institucionais destes sujeitos. Assim, evidenciando os paradigmas sociais e históricos que perpetuam a invisibilização dessa comunidade (PINTO et al., 2015).

Somando-se a isso, em meados do século XIX, o conceito de instinto torna-se uma categoria a ser estudada, associando os desejos e comportamentos fora do "normal" no âmbito psiquiátrico, como algo patológico e perverso. Como resultado, têm-se a patologização da homossexualidade (GARCIA; MATTOS, 2020). Descrita como homossexualismo, apenas em 1973 tal concepção foi retirada dos manuais de doenças mentais como o DSM (Manual Diagnóstico e Estatístico de Transtornos Mentais) em razão de pressões sociais e políticas (Neto et al., 2020).

Por meio da literatura, mais precisamente na novela Bom Crioulo, de Adolfo Caminha, em 1896, o Brasil se tornou o primeiro país com registros sobre o termo "homossexualismo", tratado como um distúrbio a ser tratado e curado. Sendo assim, o tratamento para a "cura" da homossexualidade ainda é buscado por pais/responsáveis de crianças/adolescentes LGBT+, e por adultos que desejam obter o suposto tratamento (MACEDO; SIVORI, 2018). Diante das possíveis intervenções realizadas visando a cura da homossexualidade, os autores (2018) salientam que elas:

\footnotetext{
... consistem em intervenções cirúrgicas como castração, vasectomia, lobotomia, esterilização, clitorodectomia e histerectomia; intervenções químicas com estimulação sexual, indução de depressão sexual e injeção de hormônios (estrogênio e testosterona), e intervenções psicológicas, como a prescrição de abstinência, terapia de ajustamento, psicanálise, hipnose e terapia aversiva (MACEDO; SIVORI, 2018, p. 4).
} 
Ainda no ano de 2009, foram levantados casos em âmbito nacional sobre psicólogos ligados a instituições religiosas que estavam ofertando supostos tratamentos para a "cura gay". Quando questionados sobre a acusação, alegaram a ideia pautada na constituição homoerótica do desejo, constituindo-a como uma patologia, uma anormalidade, um disfuncionamento. Esse estado de dita normalidade pode ser caracterizado como "heterossexualidade genital compulsória" e pode estar contida em âmbito jurídico, social e na saúde (DUNKER; NETO, 2010).

O Brasil é um país tradicionalmente atrelado à religião e, em grande parte, às crenças cristãs. Nelas, a rejeição quanto à diversidade sexual está presente, evidenciando-se pela resistência em pensamentos sistêmicos e conservadores os quais obstruem novas percepções quanto às concepções de orientação sexual e identidade de gênero. Tal discurso é representado pelo protestantismo norte-americano e pelo pensamento puritano, os quais refletem a sexualidade pautada por normas que têm como finalidade a procriação e o matrimônio. Esses discursos buscam sua justificativa no Antigo Testamento para sustentar prerrogativas naturalistas sobre a sexualidade. Com isso, atrela-se a homossexualidade a uma escolha imoral que acentuando um apego aos parâmetros heteronormativos e remete à concepções preconceituosas a respeito da população LGBT+ (MACEDO; SIVORI, 2018).

Outro impasse sócio-institucional brasileiro dirigido à população LGBT+ é o acesso insuficiente ao sistema de saúde pela comunidade LGBT+, mostrando-se limitado e com um menor número de buscas. Isto deve-se ao atendimento discriminatório, não humanizado e cheio de estigmas sobre a diversidade sexual. Dessa forma, a abordagem do atendimento sobre a saúde e a violência dos indivíduos LGBT+ revela-se muitas vezes estigmatizada, dificultando o cuidado e a manutenção da saúde física e mental das pessoas LGBT+ (PINTO et al., 2015).

Ainda sobre o pressuposto acima, os autores remetem sobre a discriminação ocorrida no atendimento de saúde

Estudo realizado em capital do nordeste brasileiro com análise dos sentidos atribuídos por 15 agentes comunitários de saúde (ACS) ao cuidado em saúde à população LGBT mostrou que há estigma e preconceito na assistência à saúde e que os profissionais entrevistados trazem concepções tradicionais e heteronormativas para seu trabalho. Além disso, identificou-se pouco conhecimento sobre a política de equidade, baixa implantação de suas diretrizes na atenção básica e escassa oferta de capacitação para ACS (PINTO et al., 2015, p. 9).

Esse ponto se torna um agravante à tal problemática de saúde pública, dificultando a assistência profissional e ética à comunidade em questão e intensificando o seu incipiente cuidado e atenção à população LGBT+.

Em virtude da rejeição, da discriminação, da falta de acolhimento e de respeito existentes no meio social, nas escolas, nas famílias e nas instituições em geral, "sair do armário" tem-se mostrado uma atitude complexa, marcada por sentimentos ambivalentes de dúvida frente à sua revelação, mesmo que esta seja possível. Assim sendo, o ato de revelar-se não está imune à lógica moderna social 
hegemônica - regida por parâmetros binários e naturalizados de exercício da sexualidade - que visa a obediência e a docilização dos corpos desejantes. Para tanto, na medida em que algum de seus membros são considerados como desviantes da norma, a família pode acabar se dispondo de dispositivos violentos, de físicos à psicológicos, objetivando enquadrá-los à referida norma (PERUCCHI; BRANDÃO; VIEIRA, 2014).

Não obstante, de acordo com o Atlas da Violência 2019, publicado pelo Instituto de Pesquisa Econômica Aplicada (IPEA), a gravidade da violência contra a população LGBT+ é ampliada em virtude da invisibilidade dessa questão, uma vez que reflete-se na produção de dados oficiais e estatísticos. Nesse quesito, o IPEA afirma que o IBGE (Instituto Brasileiro de Geografia e Estatística) não faz qualquer pergunta nos seus surveys domiciliares a respeito da orientação sexual, o que contribui para que não haja uma noção exata de quantas pessoas pertencem à população LBGT+. Somando-se a isso, na efetuação dos registros, as polícias (de maneira geral) não fazem qualquer classificação das vítimas de violência de acordo com suas respectivas orientações sexuais. Tal dado, inclusive, mostra-se inexistente nas declarações de óbito. Diante de tudo, torna-se árduo dimensionar e traçar diagnósticos a fim de que sejam produzidas políticas públicas que venham a mitigar a violência contra a população LGBT+.

\section{A VIOLÊNCIA NO CONTEXTO INTRAFAMILIAR CONTRA A POPULAÇÃO LGBT+ E A PANDEMIA POR COVID-19 COMO AGRAVANTE}

Mesmo havendo a escassez e falta de qualidade das informações sobre a população LGBT+, por meio dos dados que puderam ser coletados no Disque 100 e no Sinan (Sistema de Informação de Agravos de Notificação), constata-se o aumento de casos de violência contra a população LGBTI+ no Brasil (IPEA, 2019).

Dentre os locais em que ocorreram as maiores taxas de homicídio da população LGBT+, prevaleceram as vias públicas e as residências das vítimas (MENDES; SILVA, 2020). À vista disso, dos casos de violências notificadas, tem-se que os autores mais frequentes foram os familiares da vítima, o que torna a instituição familiar um potencial espaço para a ocorrência dos primeiros casos de violências contra jovens LGBT+ (PINTO et al., 2015).

A violência intrafamiliar, portanto, pode ser compreendida como quaisquer atitudes que venham prejudicar o bem-estar e os desenvolvimentos físico, mental e social, praticados por algum familiar, manifestando-se sob forma de agressão, de negligência e de abusos físico, sexual e psicológico (ANTUNES; MACHADO; MALTA, 2020). Assim, na medida em que afeta significativamente a saúde das pessoas à ela submetida, a violência intrafamiliar se configura como um problema de saúde pública (BRASIL, 2001).

Este tipo de violência é cometida por algum membro da família, incluindo pessoas que passam a assumir função parental mesmo que não haja laço consanguíneo, mas que tenha um vínculo 
de poder sobre a vítima. Tal violência pode ocorrer tanto dentro como fora do ambiente doméstico, haja vista que o conceito de violência intrafamiliar não se restringe ao espaço físico onde ocorre a violência, mas também às relações vigentes (BRASIL, 2001).

Nesse sentido, vale pontuar que considera-se como família o primeiro núcleo de socialização dos indivíduos, que é constituído por um grupo de pessoas com vínculos afetivos, de consanguinidade ou de convivência. Apesar de a estrutura familiar se modificar de acordo com os contextos sociais, culturais e históricos de uma dada sociedade, em seu meio, são transmitidos valores, usos e costumes os quais irão auxiliar na formação da personalidade e da bagagem emocional das pessoas nela incluídas (BRASIL, 2001).

No meio intrafamiliar, as regularidades presentes no âmbito da vida cotidiana passam a ser quase que espontaneamente assimiladas por seus membros. Por meio deste viés, a heteronormatividade atua, fazendo com que formas de discriminação e de violência vigentes em contextos diversos da sociedade em geral se reproduzam no micro contexto familiar (PERUCCHI; BRANDÃO; VIEIRA, 2014).

Somando-se a isso, apesar de a violência intrafamiliar ser concebida como um problema social de ampla dimensão e que abarca toda sociedade, afeta, principalmente, mulheres, crianças, adolescentes, idosos e portadores de deficiência (BRASIL, 2001). Entretanto, as crianças e os adolescentes são as principais vítimas, principalmente em se tratando da violência intrafamiliar (ANTUNES; MACHADO; MALTA, 2020), haja vista os inúmeros casos de subnotificação (BRASIL, 2001). Ademais, segundo o IPEA (2019), nos últimos anos, está ocorrendo um aumento da violência letal contra as pessoas negras, LGBT+ e mulheres.

A partir do exposto, pode-se compreender o dilema vivenciado não apenas pelas pessoas LGBT+, de modo geral, que são vítimas de violência em suas famílias, mas também aquelas que são mulheres, crianças, adolescentes, idosos e portadores de deficiência que, mais frequentemente, encontram-se em situação de maior vulnerabilidade. Isto não apenas em decorrência da heteronormatividade que impõe ao homem adulto heterossexual a necessidade de ser o provedor familiar, mas em virtude da presença de dependência econômica, emocional, afetiva ou em decorrência de limitações cognitivas, físicas e assim por diante.

Sob esse aspecto, o estudo de Soliva e Junior, efetuado em 2014, buscou compreender a vivência de adolescentes homossexuais frente às relações com seus familiares. Contando com a participação de 12 adolescentes homossexuais, com idade de 18 e 19 anos, que relataram as reações dos familiares ao descobrirem a sexualidade dos referidos jovens. A maioria dos casos, foi marcada pela reação negativa, havendo a exteriorização de falas preconceituosa, de sentimentos de decepção gerada pela queda da expectativa heterossexual normativa, havendo familiares que deixaram de falar com os jovens.

Além das vulnerabilidades no contexto intrafamiliar a que estão expostos os sujeitos LGBT+, diante da pandemia causada pela síndrome respiratória aguda grave do COVID-19 e por suas altas taxas de infecção e de contágio, diversos países, incluindo o Brasil, iniciaram o processo de 
afastamento social e de isolamento domiciliar. Diante disso, múltiplas famílias tiveram o seu cotidiano transformado, necessitando modificá-lo a fim de encaixar suas tarefas, estudos e demais afazeres de acordo com as novas regras de isolamento social.

Motivado pelo isolamento domiciliar, houve o agravamento da violência intrafamiliar contra membros da comunidade LGBT+, já que constatou-se o aumento de notificações de violência física ocorrida principalmente no espaço privado. À exemplo disso, foi realizado um estudo etnográfico em Santa Maria (RS) com travestis, o qual revelou que a residência é um dos locais que mais manifestam atitudes violentas, preconceituosas e de discriminação, o que pode acarretar na saída de casa a fim de manter a saúde física e mental dos indivíduos LGBT+ (PINTO et al., 2020). Além de correrem o risco de ficar em situação de sem-abrigo e de viver em condições precárias, as pessoas LGBT+ apresentam maior risco de desenvolver sintomatologia depressiva, ansiogênica e de cometer suicídio (NEVES, 2019).

Diante disso, vale considerar que

Em geral, os casos de violência no Brasil são registrados em situações policiais, tratando-se, portanto, de casos de violência explícita, facilmente constatada. Porém, existem casos de violência psicológica, difíceis de serem percebidos e diagnosticados, tanto no nível institucional quanto pelo agressor ou pela própria vítima. A constante desmoralização do outro, por exemplo, é uma dessas formas. Os efeitos morais da desqualificação sistemática de uma pessoa, principalmente nas relações familiares, representa uma forma perversa e cotidiana de abuso cujo efeito é tão ou mais pernicioso que qualquer outro, já que pode promover distúrbios graves de conduta na vítima. Não encontrando recursos para se proteger, a vítima estará exposta a respostas cada vez mais violentas por parte do agressor (BRASIL, 2002, p. 10).

É necessário destacar que a violência no âmbito familiar promove fatores estressores, o que contribui com o aumento de efeitos negativos relacionados à saúde mental da população LGBT+. A homofobia internalizada (H.I.) é um dos aspectos sociais que mais dizem respeito à baixa autoestima da pessoa LGBT+. A H.I. é caracterizada como a estigmatização e preconceito contra a comunidade por um sujeito pertencente a ela. Esse aspecto vem a decorrer por conta da heteronormatividade social, que introjeta no indivíduo a negação em relação à sua própria sexualidade e identidade de gênero. Assim, o estresse psicológico e a saúde mental são afetados pelas crenças negativas a respeito de si mesmo. Além disso, a falta de conectividade das pessoas LGBT+ com a sua comunidade também são aspectos que dificultam no apoio e comunicação (PAVELTCHUK; BORSA, 2019).

Nesse contexto, a família assume um papel que não contempla a proteção e a promoção de saúde e nem da dignidade aos indivíduos LGBT+. Dessa maneira, atua, portanto, como um dispositivo de reiteração violenta que repercute na inferiorização das experiências desviantes, que, além disso, muitas vezes, faz com que as vítimas não consigam perceber que vivenciam situações discriminatórias e de violência (PERUCCHI; BRANDÃO; VIEIRA, 2014).

Ao passo que a família não se mostra como uma rede de apoio, mas sim de opressão, muitos desses jovens, na tentativa de dividir as suas experiências e dificuldades, acabam recorrendo aos amigos 
e/ou amigas. Contudo, apesar de esses vínculos afetivos serem capazes de promover o bem-estar e o desenvolvimento da identidade dos sujeitos, podem, por outro lado, serem potencializadores de mal estar e adoecimento (PERUCCHI; BRANDÃO; VIEIRA, 2014). Para tanto, a busca por ajuda profissional se faz amplamente necessária.

\section{SAÚDE DA POPULAÇÃO LGBT+ E O PAPEL DA PSICOLOGIA}

No final do século XIX, quando a Psicologia adentrou no âmbito daquilo que era tomado como ciência, o viés patologizante das práticas sexuais entre pessoas do mesmo gênero já estava presente no discurso da ciência médica. Assim, em seus primórdios, a Psicologia se associou aos padrões moralistas da época, assumindo a heterossexualidade como essencial, natural e normal. Partindo disso, houve a produção de conhecimentos, a imposição de diagnósticos, a proposição de tratamentos e a elaboração de propostas terapêuticas no intuito de reorientar a sexualidade dos sujeitos com "desvio sexual” em direção à heterossexualidade (ANZOLIN; MOSCHETA, 2019).

Tal paradigma passou a ser repensado somente por volta da década de 1970, em virtude do surgimento de movimentos militantes LGBT+ que afirmavam a diversidade sexual como possibilidade legítima de existência humana. Assim, em 1973 desvinculou-se a homossexualidade do Manual Diagnóstico de Transtornos Mentais (DSM) e, apenas de 2018 para 2019, retirou-se a vivência trans do âmbito dos transtornos mentais da $11^{\mathrm{a}}$ versão do CID. Diante disso, no cenário atual da Psicologia, apesar de haver grande força em prol da diversidade sexual, ainda pode-se encontrar movimentos que se contrapõem à isso, reivindicando o direito de propor o "tratamento" da homossexualidade (ANZOLIN; MOSCHETA, 2019).

Em paralelo à essa reivindicação, um dos estigmas que mais perpetuaram por meio da cultura judaico-cristã foi o julgamento dos homens chamados sodomitas, os quais mantinham relações sexuais com outros homens. Estes homens foram perseguidos em alguns países da Europa pré-moderna, pois essa prática configurava-se como crime. A justificativa vigente era pautada com base na afirmação de que o ato era postulado como incitação demoníaca (TOLEDO; PINAFI, 2012).

No modelo da clínica psicanalítica, a homossexualidade foi durante muito tempo classificada junto aos distúrbios mentais, neurose e perversão. Visando garantir uma clínica com caráter inovador, para além da abordagem teórica, o terapeuta deverá tomar alguns caminhos na terapia, como o de convidar o paciente a compreender sua orientação sexual enquanto aliada a sentimentos positivos de sustentação à vida. Além disso, deverá utilizar uma linguagem não heteronormatizada, auxiliando o paciente a reelaborar as crenças negativas presentes sobre a sua sexualidade (TOLEDO; PINAFI, 2012).

Em sintonia, o Conselho Federal de Psicologia (CFP), na resolução número 001/99, de 22 de março de 1999, estabeleceu normas para a atuação das(os) psicólogas(os) em relação à questão da Orientação Sexual. Dentre o que nela é resolvido, tem-se: 
Art. $1^{\circ}$ - Os psicólogos atuarão segundo os princípios éticos da profissão notadamente aqueles que disciplinam a não discriminação e a promoção e bem-estar das pessoas e da humanidade; Art. $2^{\circ}$ - Os psicólogos deverão contribuir, com seu conhecimento, para uma reflexão sobre o preconceito e o desaparecimento de discriminações e estigmatizações contra aqueles que apresentam comportamentos ou práticas homoeróticas; Art. $3^{\circ}$ - os psicólogos não exercerão qualquer ação que favoreça a patologização de comportamentos ou práticas homoeróticas, nem adotarão ação coercitiva tendente a orientar homossexuais para tratamentos não solicitados - Parágrafo único - Os psicólogos não colaborarão com eventos e serviços que proponham tratamento e cura das homossexualidades; Art. $4^{\circ}$ - Os psicólogos não se pronunciarão, nem participarão de pronunciamentos públicos, nos meios de comunicação de massa, de modo a reforçar os preconceitos sociais existentes em relação aos homossexuais como portadores de qualquer desordem psíquica (CFP, 1999, p. 2).

Somando-se a isso, o CFP, no Código de Ética Profissional do Psicólogo (2005), assinala, em seus primeiro, segundo e terceiro tópicos dos Princípios Fundamentais que norteiam a profissão, o seguinte:

I. O psicólogo baseará o seu trabalho no respeito e na promoção da liberdade, da dignidade, da igualdade e da integridade do ser humano, apoiado nos valores que embasam a Declaração Universal dos Direitos Humanos; II. O psicólogo trabalhará visando promover a saúde e a qualidade de vida das pessoas e das coletividades e contribuirá para a eliminação de quaisquer formas de negligência, discriminação, exploração, violência, crueldade e opressão; III. O psicólogo atuará com responsabilidade social, analisando crítica e historicamente a realidade política, econômica, social e cultural (CFP, 2005, p. 7).

O referido código (2005) postula, ainda, que, dentre as atitudes que são vedadas à(ao) Psicóloga(o), tem-se: "Praticar ou ser conivente com quaisquer atos que caracterizem negligência, discriminação, exploração, violência, crueldade ou opressão"(p. 9); e "Induzir a convicções políticas, filosóficas, morais, ideológicas, religiosas, de orientação sexual ou a qualquer tipo de preconceito, quando do exercício de suas funções profissionais" (CFP, 2005, p. 9).

Contudo, à exemplo da homofobia, sabe-se que ela se constitui como um fenômeno complexo e multifacetado cujas dimensões psicológicas e sociais se arquitetam em um sistema de opressão que abarca os âmbitos intraindividual, individual, interacional, institucional e social. Assim sendo, tal sistema discriminatório acerca da orientação sexual detém algumas diversidades que estão atreladas a aspectos como raça, etnia, classe, geração e gênero. Assim sendo, a homofobia atinge diferentemente cada um dos sujeitos, de acordo com a localização deles em relação à hierarquia social (PERUCCHI; BRANDÃO; VIEIRA, 2014).

Dessa maneira, independentemente do contexto, sabe-se que as pessoas LGBT+ sofrem maiores discriminações e são mais vítimas de exclusão do que as pessoas heterossexuais e cissexuais. Não raras as vezes, além de essa população ser vitimizada apenas por sua identificação como lésbicas, gays, bissexuais ou trans, ainda podem ser vítimas de violência no ambiente doméstico (NEVES, 2019).

Esse condensamento de vulnerabilidades torna a intervenção profissional muito complexa (NEVES, 2019). Mostrando-se como um problema de saúde pública de grande amplitude, faz-se 
necessário para o enfrentamento da violência intrafamiliar o envolvimento não apenas uma efetiva mobilização de diversos setores do governo e da sociedade civil, mas, também, de profissionais de diferentes áreas de atuação (BRASIL, 2001), que necessitam de de uma formação contínua e especializada (NEVES, 2019), uma vez que perceber e registrar os casos de violência intrafamiliar vem sendo um desafio para profissionais de todas as áreas (BRASIL, 2001).

Para tanto, é imprescindível não apenas que as vítimas busquem auxílio, mas também que aqueles que testemunham os casos de violência busquem ajuda. Dentre as possibilidades disponíveis, estão: o Disque 100, que funciona 24 horas por dia; o Disque Saúde, ou Disque 136; a Central de Atendimento à Mulher, ou Disque 180; os serviços ofertados pelo SUS (Sistema Único de Saúde), como o SUAS (Sistema Único de Assistência Social) e a equipe multiprofissional da ESF (Estratégia Saúde da Família) nas Unidades Básicas de Saúde (UBSs). Ademais, a realização de boletins de ocorrência podem ser feitos online. Contudo, pode-se recorrer às Delegacias de Defesa da Mulher e às instituições Casa da Mulher Brasileira, que funcionam 24 horas e contemplam os suportes psicológico, jurídico e de assistência social.

Ao que concerne às possibilidades da atuação em Psicologia, além daquilo que é estabelecido com Código de Ética Profissional do Psicólogo (2005) e nas demais resoluções, principalmente a de número 001/99 (de 22 de março de 1999), as(os) Psicólogas(os) podem estimular o aprendizado de empatia e diminuir os casos de LGBTfobia. Tal objetivo pode ser atingido por meio de palestras, debates, divulgação de pesquisas científicas, dentre outras possibilidades, de conteúdos que abordem não apenas o que é diversidade sexual, mas também sobre o que é violência, em quais ambientes ela está presente, de que formas pode aparecer e o que se fazer perante ela.

Vale considerar, também, que, no meio do contexto pandêmico provocado pelo COVID-19, o distanciamento físico tem imposto barreiras e desafios à atuação profissional dos agentes de saúde. Incluída nesse âmbito, a Psicologia se viu obrigada a investir maiores energias em sua atuação por meios remotos. Diante disso, o Conselho Federal de Psicologia elaborou, além da resolução de número 11, de 11 de maio de 2018, a resolução número 4, de 26 de março de 2020, que dispõe acerca da regulamentação dos serviços psicológicos prestados por meio de Tecnologia da Informação e da Comunicação durante a pandemia do COVID-19.

\section{CONSIDERAÇÕES FINAIS}

Pautado nos objetivos que direcionaram a elaboração do que aqui foi dissertado, o vigente estudo visou, acima de tudo, refletir acerca da violência à população LGBT+ no contexto intrafamiliar em tempos de pandemia da COVID-19, trazendo aspectos históricos e socioculturais que auxiliaram em uma melhor compreensão da problemática abordada.

Contudo, na medida em que se sucedia a elaboração do artigo, algumas adversidades emergiram. Uma delas se deu em virtude da dificuldade em encontrar dados confiáveis a respeito da violência contra 
a população $\mathrm{LGBT}+$, principalmente no âmbito intrafamiliar. Atrelado a isso, havia poucos estudos que abordavam, especificamente, o que foi trazido em nosso estudo: a violência contra à população LGBT+ no contexto intrafamiliar em tempos de pandemia da COVID-19. Assim sendo, as autoras do presente estudo almejaram, por meio de uma costura teórica, abordar essa questão.

Diante disso, cabe frisar que o aqui construído possui limitações, não apenas por ser elaborado em uma quantidade de páginas que é ínfima em relação à complexidade da temática, mas, também, ao caráter atual do que é contemplado. Para tanto, sugere-se a realização de novos estudos a fim de que a compreensão acerca do fenômeno da violência contra à população LGBT+ no contexto intrafamiliar em tempos de pandemia da COVID-19 seja tanto qualitativamente como quantitativamente ampliada.

Somando-se a isso, as autoras deste estudo ressaltam que a invisibilidade respectiva às demandas da população LGBT+ reflete, também, no âmbito acadêmico. Portanto, acreditamos que se deve incentivar mais a produção científica realizada, principalmente, por pessoas LGBT+, ampliando seu espaço de fala. Com isso, as singularidades de suas vivências poderão enriquecer as possibilidades de atuação não apenas dos profissionais da saúde, mas também de toda a esfera social.

\section{REFERÊNCIAS}

ALBERNAZ, R. O.; KAUSS, B. S. Reconhecimento, igualdade complexa e luta por direitos à população LGBT através das decisões dos tribunais superiores no Brasil. Revista Psicologia Política, v. 5, n. 34, p. 547-561, 2015. Disponível em: https://bit.ly/3n9E3PP. Acesso em: 28 de jan. de 2021.

ANTUNES, J. T.; MACHADO, Í. E.; MALTA, D. C. (2020). Fatores de risco e proteção relacionados à violência intrafamiliar contra os adolescentes brasileiros. Revista Brasileira de Epidemiologia, v. 23, n. e200003, supl., p. 1-13, 2020. Disponível em: https://bit.ly/3vpYQCd. Acesso em: 06 de fev. de 2020 .

ANZOLIN, B.; MOSCHETA, M. S. Sentidos sobre Diversidade Sexual e o Trabalho de Psicólogas na Atenção Básica. Psicologia: Ciência e Profissão, v. 39, n. spe 3, e228644), p. 206-221, 2019. Disponível em: https://bit.ly/3vmdzhq. Acesso em: 10 de fev. de 2020.

AUGUSTO, C. A. et al. Pesquisa Qualitativa: rigor metodológico no tratamento da teoria dos custos de transação em artigos apresentados nos congressos da Sober (2007-2011). Revista de Economia e Sociologia Rural, v. 51, n. 4, p. 745-764, 2013. Disponível em: https://bit.ly/31TLFGy. Acesso em: 21 de nov. de 2020.

BARDIN, L. Análise de conteúdo. 1. ed. São Paulo, SP: Edições 70, 2011. 
BRASIL; Ministério da Saúde; Secretaria de Políticas de Saúde. Violência intrafamiliar: orientações para prática em serviço. Secretaria de Políticas de Saúde. Brasília: Ministério da Saúde, 2001. Disponível em: https://bit.ly/3FZeRUr. Acesso em: 07 de fev. de 2021.

CONSELHO FEDERAL DE PSICOLOGIA (CFP). Resolução CFP Nº01/99, de 22 de março de 1999. Estabelece normas de atuação para os psicólogos em relação à questão da Orientação Sexual. Conselho Federal de Psicologia, Brasília, 1999. Disponível em: https://bit.ly/3n8gbf8. Acesso em: 04 de fev. de 2021.

CONSELHO FEDERAL DE PSICOLOGIA (CFP). Resolução CFP No 010/05, de 21 de julho de 2005. Aprova o Código de Ética Profissional do Psicólogo. Conselho Federal de Psicologia, Brasília, 2005. Disponível em: https://bit.ly/3DWZcU5. Acesso em: 04 de fev. de 2021.

CONSELHO FEDERAL DE PSICOLOGIA (CFP). Resolução CFP Nº 011, de 21 de maio de 2018. Regulamenta a prestação de serviços psicológicos realizados por meios de tecnologias da informação e da comunicação e revoga a Resolução CFP nº 11/2012. Conselho Federal de Psicologia, Brasília, 2018. Disponível em: https://bit.ly/3G1xg31. Acesso em: 12 de fev. de 2021.

CONSELHO FEDERAL DE PSICOLOGIA (CFP). Resolução CFP Nº 4, de 26 de março de 2020. Dispõe sobre regulamentação de serviços psicológicos prestados por meio de Tecnologia da Informação e da Comunicação durante a pandemia do COVID-19. Conselho Federal de Psicologia, Brasília, 2020. Disponível em: https://bit.ly/3DPGTA4. Acesso em: 12 de fev. de 2021.

DUNKER, C. I. L.; KYRILLOS NETO, F.. Curar a Homossexualidade?: a psicopatologia prática do DSM no Brasil. Revista Mal Estar e Subjetividade, v. 10, n. 2, p. 425-4460, 2010. Disponível em: https://bit.ly/3pawvih. Acesso em: 30 de janeiro de 2021.

FOUCAULT, M. História da sexualidade I: A vontade de saber. Rio de Janeiro, RJ: Graal, 1988. GARCIA, A, M. R. V.; MATTOS, A. R. “Terapias de Conversão": Histórico da (Des)Patologização das Homossexualidades e Embates Jurídicos Contemporâneos. Psicologia: ciência e profissão, v. 39, n. spe3, e228550, 2019. Disponível em: https://bit.ly/3pmv1kS. Acesso em: 29 de jan. de 2021

INSTITUTO DE PESQUISA ECONÔMICA APLICADA (IPEA), Fórum Brasileiro de Segurança Pública. Atlas da violência 2019. Brasília; Rio de Janeiro; São Paulo: Instituto de Pesquisa Econômica Aplicada; Fórum Brasileiro de Segurança Pública, 2019. Disponível em: https://bit.ly/3BY1TUH. Acesso em: 12 de fev. de 2021. 
MACEDO, C. M. R.; SIVORI, H. F. Repatologizando a homossexualidade: a perspectiva de "psicólogos cristãos" brasileiros no século XXI. Estudos e Pesquisas em Psicologia, v. 18, n. spe, p. 1415 1436, 2018. Disponível em: https://bit.ly/3AZwFvi. Acesso em: 30 de jan de 2021.

MENDES, W. G.; SILVA, C. M. F. P. Homicídios da População de Lésbicas, Gays, Bissexuais, Travestis, Transexuais ou Transgêneros (LGBT) no Brasil: uma Análise Espacial. Ciência \& Saúde Coletiva, v. 25, n. 5, p. 1709-1722, 2020. Disponível em: https://bit.ly/3ATWaOj. Acesso em: 12 de fev. de 2021.

MINAYO, M. C. S. Ciência, técnica e arte: o desafio da pesquisa social. In: MINAYO, M. C. S. (Org.). Pesquisa social: Teoria, método e criatividade 22. ed. Petrópolis, RJ: Editora Vozes, 1994.

MORAIS NETO, A. C. D. et al. Ensino em Saúde LGBT na Pandemia da Covid-19: Oportunidades e Vulnerabilidades. Revista Brasileira de Educação Médica, v. 44, n. supl. 1, e157, 2020. Disponível em: https://bit.ly/3aLKmTT. Acesso em: 28 de jan. de 2021.

NEVES, A. S. A intervenção profissional junto de vítimas de violência doméstica LGBT. Psicologia \& Sociedade, v. 31, n. e184522, p. 1-4, 2019. Disponível em: https://bit.ly/3DSprLj. Acesso em: 20 de fev. de 2021.

PAVELTCHUK, F. O.; BORSA, J. C. Homofobia internalizada, conectividade comunitária e saúde mental de uma amostra de indivíduos LGB brasileiros. Avances en Psicología Latinoamericana, v. 37, n. 1, p. 47-61, 2019. Disponível em: https://bit.ly/3BV8f7m. Acesso em: 22 de fev. de 2021.

PERUCCHI, J.; BRANDÃO, B. C.; VIEIRA, H. I. S. Aspectos psicossociais da homofobia intrafamiliar e saúde de jovens lésbicas e gays. Estudos de Psicologia, v. 19, n. 1, p. 67-76, 2014. Disponível em: https://bit.ly/3ASNHen. Acesso em: 06 de fev. de 2021.

PINTO, I. V. et al. Perfil das notificações de violências em lésbicas, gays, bissexuais, travestis e transexuais registradas no Sistema de Informação de Agravos de Notificação, Brasil, 2015 a 2017. Revista Brasileira de Epidemiologia, v. 23, n. Suppl 01, p. 1-13, 2020. Disponível em: https://bit.ly/ 3pevoyb. Acesso em: 23 de nov. de 2020.

SOUZA, M. T.; SILVA, M. D.; CARVALHO, R. Revisão integrativa: o que é e como fazer. Einstein (São Paulo), v. 8, n. 1, p. 102-106, 2010. Disponível em: https://bit.ly/3DT1ING. Acesso em: 21 de nov. de 2020. 
SOLIVA, T. B.; SILVA JUNIOR, J. B. Entre revelar e esconder: pais e filhos em face da descoberta da homossexualidade. Sexualidad, Salud y Sociedad (Rio de Janeiro), n. 17, p. 124-148, 2014. Disponível em: https://bit.ly/3DTpNRP. Acesso em: 20 de nov. de 2020.

TOLEDO, L. G.; PINAFI, T. A clínica psicológica e o público LGBT. Psicologia clínica, v. 24, n. 1, p. 137-163, 2012. Disponível em: https://bit.ly/3n62WM7. Acesso em: 22 de fev. de 2021. 